\title{
STRATEGIC INFORMATION SYSTEM (SIS) OF VIRTUAL ORGANIZATION (VO)
}

\author{
Brane Semolic ${ }^{1}$, Jure Kovac ${ }^{2}$ \\ ${ }^{1}$ Project \& Technology Management Institute, Faculty of Logistics, \\ University of Maribor, Slovenia, brane.semoli@ siol.net \\ ${ }^{2}$ Faculty of Organizational Sciences, University of Maribor, SLOVENIA \\ jure.kovac@fov.uni-mb.si
}

\begin{abstract}
In the modern business world, the networked organizational connections tend to become prevailing organizational form. However, virtual organizations represent a special form of network organization. The backbone of virtual organization is its information system. To obtain successful and efficient operating of virtual organization, its strategic information system is of key importance. Strategic Information System (SIS) is a type of Information System that is aligned with business strategy and structure. SIS is designed to support and increase the competitive strength of a VO. We have upgraded Anthony's paradigm, and taken into consideration the changes in the field of organization and management of modern network companies. This includes also the aspect of assuring the suitable information support to corporate management, which has to provide, at different levels and areas of operation, successful and effective management of corporate business processes in virtual environment. In the paper the aspect of defining possible fields of application of the SIS and the study of their characteristics are discussed. The theory is supported and illustrated by the LENS (Laser Engineered Net Shaping) Living Laboratory case study.
\end{abstract}

\section{INTRODUCTION}

If we want to develop a competitive strength of our company, it often turns up that despite using our knowledge, capacities and other resources we are still not able to reach the desired goal. In modern business environment, the companies will establish and maintain their competitiveness not solely by optimizing their own potentials, but more often by being able to use also the resources of the others and by interconnecting them into an overall process of creating a new value. The need to connect organizations and to unite the resources has its origins in the demand posed by the global market to remain competitive concerning prices, time and quality. This is why the companies tend to be increasingly specialized and develop only those key areas that enable them to remain competitive on the global market (Milberg, Schuh, 2002, p. 21; Prahalad, Ramaswamy, 2004, p. 96). The networked organizational design is becoming the prevailing organizational form of the $21^{\text {st }}$ century.

The virtual organization's information system represents one of the key success factors. In developing an efficient virtual organization's information system, a special place belongs to the strategic information system. In this contribution, a dimension of the virtual organization's strategic information system on the example of the Living Lab case study is presented. 


\section{DEFINITION OF VIRTUAL ORGANIZATION}

One of the first contributions in dealing with the topic of virtual companies was a book by title "The Virtual Corporation" by William H. Davidow and Michael S. Malone, published in 1992. Yet, the dematerialization of the products, processes and workplaces in the organization was brought into focus of the field experts already in 1985 (and in 1987, 1994) by Abbe Mowshowitz. On the basis of established frameworks, the authors Venkatraman and Henderson in 1998 developed three gradual models of business virtuality. According to their views, virtual organizations differ from other organizations by specific abilities and by their "virtual attitude of thinking". The mentioned abilities and virtual attitude of thinking are expressed by:

- products and services that are presented to the customers "virtually", or are "virtually" consumed ("virtual encounter");

- supply processes among the organizations and by the processes inside the organizations, where the continuous processes of searching the synergistic links are carried on ("leverage-effects" and "virtual sourcing");

- knowledge in possession of the organization or among the organizations who, at different levels, connect in a flexible and non-bureaucratic way ("virtual expertise") (Venkatraman, Henderson, 1998).

Virtual organizations represent co-operation between formally disconnected organizations or persons who establish vertical or horizontal links and present themselves to the customers of their products or services as a single association. Besides this, in professional literature concerning virtual organizations there is also an obvious emphasis given to the information and communication technology as well as to the absence of the central control functions. Added to this, the time limitation of the concerned association and the geographical dispersion of the virtual organization's members are also stressed (Moldaschl, 1998, p. 19; Mohrman, Galbraith and Lawler III., 1998, p.77; Dessler, 2001, p. 230; Pettigrew and others, 2003, p. 8; Vahs, 2005, p. 507).

As indispensable precondition for the functioning of the above mentioned organizational connectedness the authors quote timely adjusted co-operative processes, organizational development, space dispersion and use of modern communication technology to master the processes of co-operation (Rohde, Rittenbruch, Wulf, 2001, p. 2).

In the literature, the companies are often described as network of companies (i. e. organizations - boundary-less firms or boundless organizations) and by this it's frequently meant a considerable number of dynamic organizations, connected in a network - i. e. virtual companies - that are linked together on a basis of interorganizational information system and guided by the aim to be successful in the area of the given projects.

\section{STRATEGIC INFORMATION SYSTEM (SIS)}

\subsection{Definition of SIS}

In theory as well as in practice, different definitions of information systems in a company are at disposal. By information systems we understand primarily the IT supported systems in companies. The most frequently used designation in the Anglo-Saxon world is "Management Information System" which is based on the 
business operations model developed in 1965 by R. Anthony ("Planning and Control Systems: A Framework for Analysis"), known also as "Anthony's Paradigm". Anthony's Paradigm could be represented in the form of a pyramid indicating the correlation and interdependence between the processes of strategic planning and managerial and operative control. By notion of managerial control are meant the procedures by which company assures successful and efficient use of its resources, whereas the operative control refers to a follow-up of the planned work execution. Five years after the publication of Anthony's Paradigm, W. Zani ("Blueprint in MIS") presented his concept of MIS, based on the latter's starting points, which should support the process of strategic planning and that of the managerial and operative control. In accordance with the nature of work and the needs of MIS users finding themselves at different levels of Anthony's pyramid, Zani speaks of two types of information system. The first one refers to the automation of business procedures, and the second one to providing information to managers for the needs of their decision making. On the basis of this original definition of MIS many different interpretations have appeared.

The next big step in development of the IT supported management information systems offering assistance to the management of a company was made in the early seventies of the previous century, when A. Gorry and M. Scott-Morton ("A Framework for Management Information Systems") presented their idea of Decision Support Systems (DSS). They defined DSS as an information system intended to support inadequately structured decision making, strategic planning, and managerial and operative controls. On these starting points later developed the concept of Executive Information System (EIS) that superstructures DSS.

In this paper, we have dealt with the concept of "Strategic Information System" (SIS), which is based on the above described findings. Its starting points were set by C. Wiseman ("Strategy and Computers - Information Systems as Competitive Weapons"), according to whom the SIS is an information system designed to support and increase the competitive strength of a company. We extended and adopted his concept to the needs of a virtual dynamic organization, where we have alliances of organizations that come together to share skills, core competences and resources in order to better respond to business opportunities. We have a set of temporary business activities which are initiated, organized and led by partners of such an organization. The VO's SIS should cover information needs of participating organizations, projects consortia, VO organizers, involved PVCs etc.

The findings of the authors dealing with the SIS, and the results of our research concerning the characteristics of contemporary corporate management have led us to the conclusion that the SIS should be considered from two aspects, i.e.:

- the aspect of defining possible fields of application of the SIS,

- his characteristics and interrelations, and

- the aspect of searching the fields of application which would, in a real case, help involved organizations to increase their competitive strength.

In our paper, we have limited ourselves to the aspect of defining possible fields of application of the SIS related to virtual dynamic organizations.

To Anthony's paradigm, which served as the starting point for the definition of the field of application of classical managerial information systems, we have added the paradigm of networked organizations that should be present in successfully operating contemporary companies. In this way we have got a modified Anthony's paradigm, shown in Figure 1. 


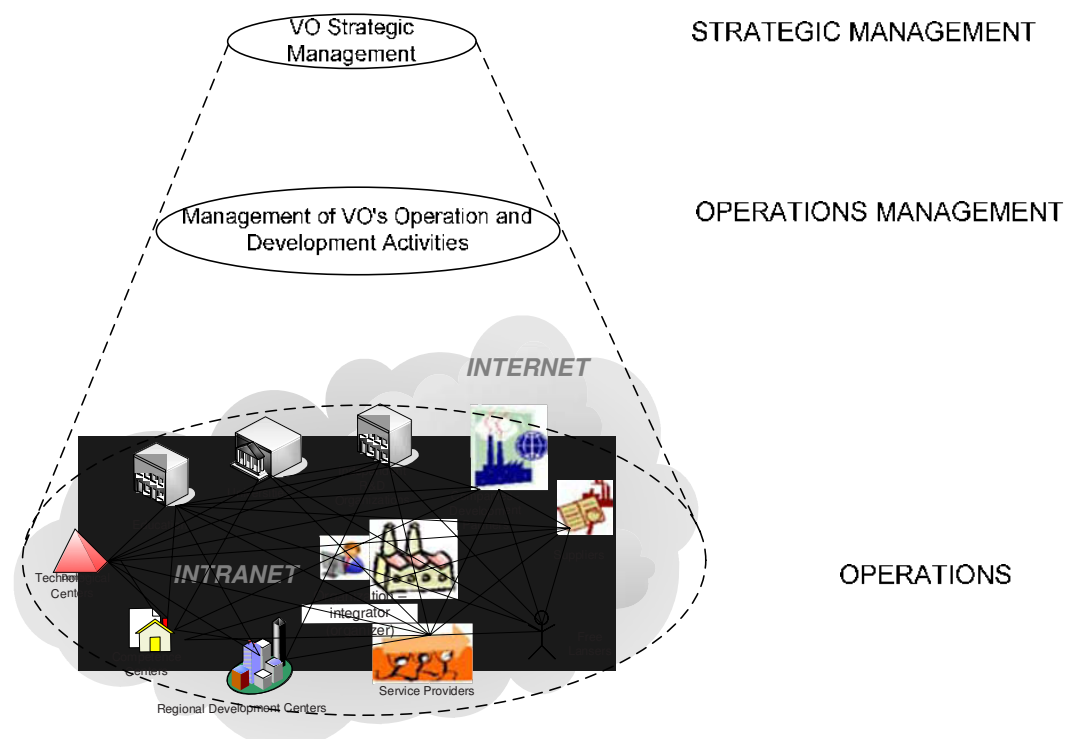

Figure 1: Modified Anthony's paradigm.

Anthony's definition of administration levels we extended on the needs of virtual dynamic organization. Through an analysis of the modified Anthony's paradigm we have reached the definition of the basic fields of application of the SIS which should provide data, information and the corresponding IT tools for the:

- implementation needs of VO's business processes,

- needs of management of VO's business activities, and

- needs of VO's executives.

According to Anthony's paradigm, it is possible, in a company, to identify three characteristic levels of decision making - the executive (top management) level, which is responsible for strategic management of a company, the medium management level, which is responsible for individual SBUs, and the business functions, projects and operations management level, which is responsible for the performance of business activities. Individual levels are interrelated, yet relatively independent in their decisions and planning.

As the business processes on the operations' level are determined, the decision processes can be structured in advance, too, and they are in this way easy to manage. There is quite a different situation on the remaining two management levels. The more we approach to the top management, whose task is strategic management of a company, the more the decision processes grow stochastic, or they can be only partly structured or not structured at all. Manager "plays" several roles. In the role of "liaison" and "leader," manager collects information which is relevant to him or her. In the role of "liaison," manager contacts people apart from his or her field of activity, and in different other ways collects information relevant to him or her. As "leader", manager collects information from his subordinates (and superiors). In the role of "monitor," manager systematically searches the environment in order to identify problems and sense opportunities. The information collected in this way is by rule communicated to the superiors - the manager plays the role of "spokesman" to the subordinates - the manager plays the role of "disseminator" - or he or she uses 
this information alone, in one of the following four managerial roles of decision maker: as "disturbance handler", "entrepreneur", "resource allocator" and "negotiator". Information technology influences all these roles; however, its influence on the role of manager as decision maker is the strongest. The versatility of decision situations, which managers or those preparing expert ground for decisions have to face, dictates different modes and scopes of application of information technology. Contemporary manager or operations analyst has at his disposal a range of information technologies which form a Decision Support Systems Group (DSSG). These are:

- Decision Systems (DS),

- Decision Support Systems (DSS),

- Expert Systems (ES),

- Group Decision Support Systems (GDSS).

The central part of DSSG represent Decision Support Systems (DSS). In practice, the notions of DSS and EIS (Executive Information Systems) are often confused. Thus, sometimes, the first or the second notion is interchangeably used for the same system. Nevertheless, the DSS and the EIS are two different systems, and they should be treated separately, as each of them is intended for different users, and they also have different purposes and modes of application.

The DSS are primarily intended for managers and experts who prepare the grounds for executive management's decisions. They help solve problems to which the solutions are not structured in advance. Usually there are several different ways to the solution of these problems. The user of such systems sets different possible scenarios of solution by using the logic "What if..." and the method of "Goal Seeking Analysis". The basis of DSS is a "model-data" combination by means of which relations between the data of the operations field in question are described. Systems should be simple and provide access to various data that make possible to form models which are basis for the performance of the said analyses.

VOs' managers need in the first place the following information:

- key (actual) problems and possible reasons,

- the most important indicators of success and effectiveness of temporary consortia in the form of planned and real values and deviations,

- financial situation in VO's operations and projects,

- key indicators of operations by areas of responsibility (e.g. by projects, activities, etc.), and

- various (consolidated) reports produced by the criteria and in the way dictated by the actual situation.

All these information refer to the success and effectiveness of the operations, adaptation and development business processes.

\section{CASE STUDY - LENS LIVING LAB}

\subsection{What is LENS Living Lab}

Lens Living Lab is a real-life research and operational laboratory with the focus on a Lens new technology applications development and operational use. The LENS Living Lab creates a base for inventing, testing, prototyping and marketing of new LENS technology applications. The major advantage of virtual organization's LENS Living Lab is creation of pools of innovative organizations and experts from 
different research and end user areas who are collaborating and cooperating in this virtual environment.

The areas of LENS Living Lab application research and operations are: Tool making and niche machines production, Automotive, Aeronautics and Medicine.

The participating organizations are divided in following groups: Material science, Mechanical Engineering, Laser and Electronics, End Users, IT and Networking Technologies.

They have been involved in three operational and research frameworks as follow (Table 2): Technological and Innovative Centre (TiC LENS), LENS Living Lab and Laser Collaboration Platform (AA LaseR).

Table 2: Co-operation and Collaboration Frameworks

\begin{tabular}{|l|l|l|}
\hline \multicolumn{1}{|c|}{ Framework } & \multicolumn{1}{c|}{ Role } & \multicolumn{1}{c|}{ Partners } \\
\hline TiC LENS & LENS Operations & LENS Consortia \\
\hline LENS Living Lab & $\begin{array}{l}\text { LENS Application } \\
\text { Research and Use }\end{array}$ & Membership \\
\hline $\begin{array}{l}\text { Laser Collaboration } \\
\text { Platform }\end{array}$ & $\begin{array}{l}\text { Wider laser community } \\
\text { collaboration }\end{array}$ & Open \\
\hline
\end{tabular}

The Figure 2 is illustration of LENS Living Lab business model. The LENS Living Lab members are business partners who have long term interest for such a cooperation. Those organizations and individuals are from research and industrial sector.

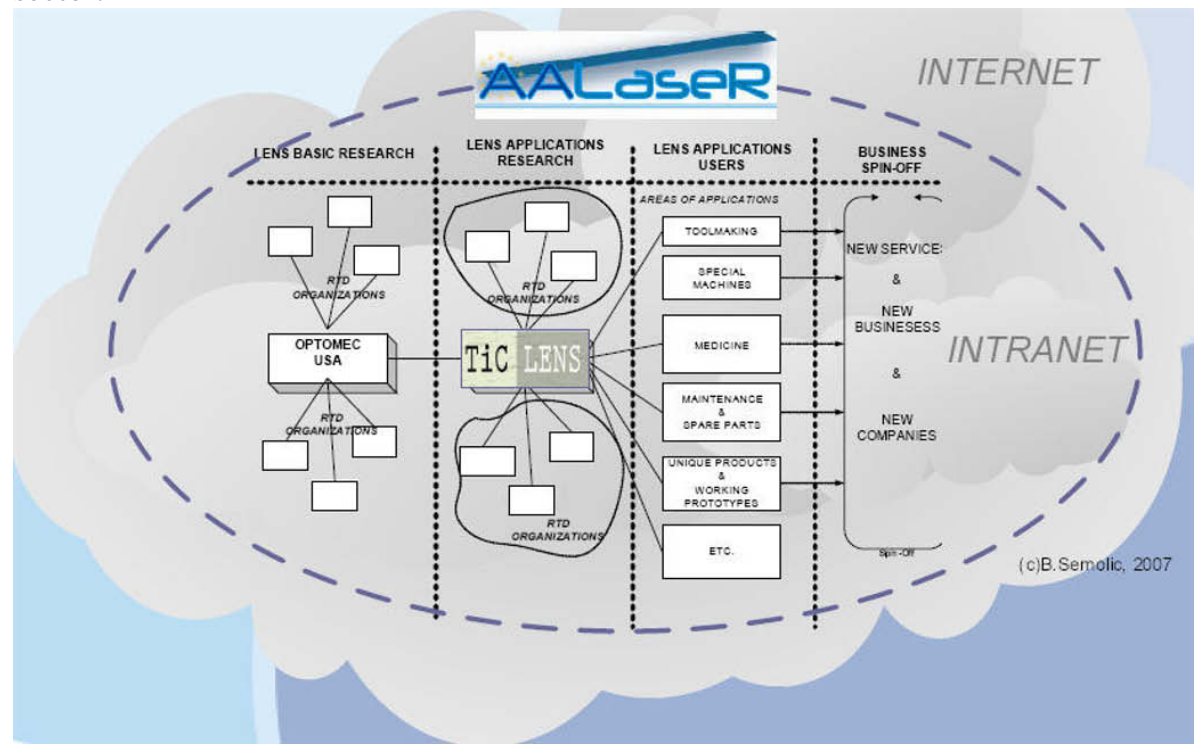

Figure 2: Draft illustration of LENS Living Lab business model

\subsection{Organization and Co-Ordination of LENS Living Lab}

The LENS Living Lab is an open network organization having three levels of interorganizational co-operation and coordination (see Figure 3). The first level deals with the strategic business issues. At this level, the participating partners sign the long-term co-operation agreement. This agreement defines the areas of cooperation and management of LENS Living Lab. The second level deals with the inter- 
organizational issues (joint and support operation and project management). This level is related to the coordination of agreed business activities and connected organizational processes. The third level of co-ordination is related to the definition of IT and telecommunication platform of co-operation.

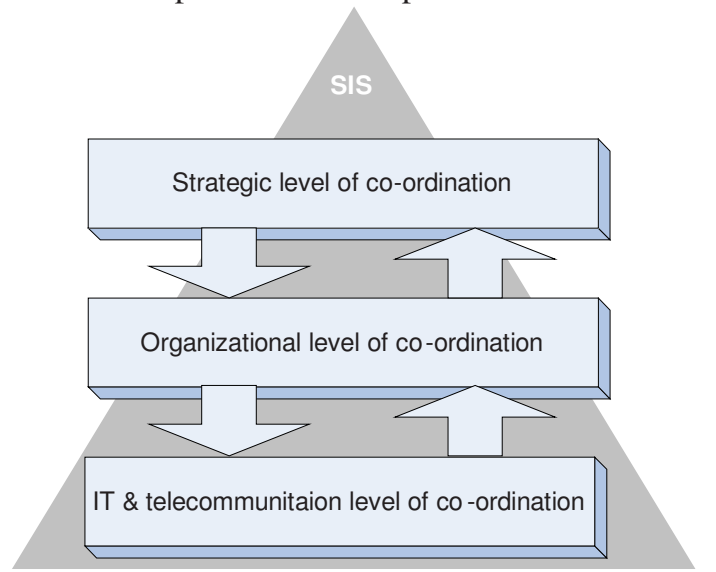

Figure 3: Levels of co-ordination in LENS Living Lab

\subsection{The Third Level of Co-Ordination ICT Tools}

The basic collaboration is usually based on phone, fax, and email communication. Although much work has been done to improve the collaborative ability among SMEs and research organizations, most of them still require suitable instruments supporting collaboration of the organizational as well as on data flow level. The lack of suitable instruments lies in the complex nature of collaboration. On the one hand, it is a question of having the right ICT tools. On the other hand, it is a question of organizational structure to allow seamless information processing as well as correct internal competencies to execute the collaborative processes typical of dynamic electronic marketplaces.

In the LENS Living Lab we are recognizing five groups of ICT tools:

- CRM (TCS portal, Tool East Solution, Video-cluster, etc),

- e-collaboration platform (Share Point, Skype, etc.),

- e-project management \& project office (Open Sourced SW),

- LENS Living Lab specific functional ICT tools (Tool East Solution, etc.) and

- LENS Living Lab Executive SW Tools (not developed yet)

The LENS Living Lab project is in progress and all decisions about the ICT tools are not finalized yet. We are using the Slovenian Toolmakers Cluster portal as the basic e-platform to build up the LENS Living Lab SIS. We are planning to use the open sourced Tool East solution to support CRM, as well as development and production processes within the network of LENS Living Lab. The Tool East solution will be operational this year. This SW has been developed by the EU consortia (partners form Slovenia, Germany, Italy, Slovakia, Bulgaria).

\section{CONCLUSIONS}

Virtual organizations are a special form of network organizations based on the modern information and communication technology and having various 
configurations. This is why we can hardly imagine a successful and efficient virtual organization's operating without a modern information and communication technology. A Living Lab is an environment in which researchers, developers and users cooperate with the common objective of delivering a tested product, solution or service respecting the users' requirements and in a shortest time possible. We used the case study of LENS Living lab to present described concept in praxis. The LENS Living Lab is an open network organization having three levels of interorganizational co-operation and coordination.

The key success factor in operating virtual organizations, as well as Living labs is their information system. One of the most important parts of it is SIS. In our concept we are using upgraded Anthony's paradigm, shown as SIS application from point of view of networked virtual organizations. For introduction of such a system into reality, the use of proper ICT tools is needed. We have grouped the tools in five specific groups.

\section{REFERENCES}

1. Beck TC. Cooperation bei der Nexwerkorganisation, IO Mangement, No.6, Zürich, BWI-ETH, 1998.

2. Bullinger HJ, Warnecke HJ, Westkamper E. Neue Organisationsformen im Untermehmen. Berlin: Springer Verlag, 2003.

3. Byrne J, Brand R, Port O. The Virtual Corporation, Business Week, (8.2.93), New York, 1993.

4. Davidov WH, Malone MS.The Virtual Corporation, New York: Harper-Collins, 1993.

5. Dessler G. Management, New Jersey: Prentice Hall Inc., 2001.

6. Eriksson, Mats; Niitamo, Veli-Pekka; Kulkki, Seija; Hribernik, Karl A. Living Labs as a MultiContextual R\&D Methodology. In: Proceedings of the ICE Conference, 2006

7. Hesselbein F, Goldsmith M, in Beckhard R. The Organization of the Future, San Francisco: JosseyBass, 1997.

8. Kelly K. New Rules for New Economy, New York: Viking Penguin. 1998.

9. Korine H, Gomez PY. The Lap to Globalization, San Francisco: Jossey-Bass, 2001.

10. Malone WT. The Future of Work, Boston: Harvard Business School Press, 2004.

11. Milber J, Schuh G. Erfolg in Netzwerk, Berlin: Springer Verlag, 2002.

12. Mohrman AS, Galbraith JR, Lawler III.E. Tomorrow's Organization, San Francisco: Jossey-Bass, 1998.

13. Moldaschl M. Kultur-Engineering und Kooperative Netzwerke, IO Mangement, Nr.6, Zürich: BWI ETH, 1998.

14. Pettigrew A, Whittington R, Melin L, Runde CS, Bosch FAJ, van den Ruigrok W, Numagami T. Innovative forms of Organizing, London: Sage Publications, 2003.

15. Prahalad CK, Ramaswamy V. The Future of Competition, Boston: Harvard Business School Press, 2004.

16. Rohde M, Rittenbuch M, Wulf V. Auf dem Weg zur virtuellen Organisation, Heidelberg: PhysicaVerlag, 2001.

17. Semolic B, Virtual and Living Laboratories, INOVA Consulting, 2006,

18. Semolic B, MIS Integration, Faculty of Business Administration and Economic, University of Maribor, 1992,

19. Semolic B, LENS Living Laboratory Project, INOVA Consulting, TCS, 2007,

20. Semolic B, AA LaseR Collaboration Platform, INOVA Consulting, TCS, 2007,

21. Semolic B, Jannicke Baalsrud Hauge, Ali Imtiaz, Richard Stevens, The Tool East Solution for Industrial Clusters in Eastern Europe, IPMA Project Management Practice, ISSUE 4, IPMA, Nijkerk, 2008

22. Semolic B and Co, LENS Living Lab Project, FP 7 project proposal, P\&TMI, Faculty of Logistics, University of Maribor, 2008

23. Vahs D. Organisation, Stuttgart: Schaffer-Poeschel Verlag, 2005.

24. Venkatraman N, Henderson JC. Real Strategis for Virtual Organizing, Sloan Management Review, 1 (40), MIT, 1998. 